\title{
Hardiness and Resilience Versus Personality Work in Visually Impaired
}

\author{
Olga Kvasova
}

Olga Savina

Moscow State University

\begin{abstract}
Personality, trauma, research last 20 years showed that people in crisis are not only injured, suffering, but able to resist, withstand also solves life problems: not only adapt, but take courage to overcome difficulties, to love, to work, to construct, to let personality grow? Theoretically described in activity-meaning approach, focusing on positive aspects of extreme situation and meaning personality work with a traumatic experience (M. MagomedEminov, 1990, 2009) so that demonstrate resilience, coping, overcoming and hardiness. The study was aimed at identifying resistance in extreme situations by the comparative analysis of discourses of people with normal vision and impaired people with its various etiologies (blind from birth and have lost their vision due to injury). We tested manifestation of resistance in people with visual impairment (congenital or acquired as a result of injury), and sighted by a "Test of hardiness" (S. Maddi) and developed life situation interview. The sample (90 people) of three groups: 1) with intact vision, 2) loss of vision due to trauma, 3) with congenital visual impairment. The overall level of viability, control and risk taking). The third group demonstrated the highest score of hardiness. Comparative analysis showed statistically significant differences in these parameters between people with congenital impairment and two other groups, differences between people who lost vision due to trauma, and sighted are not significant. Qualitative analysis of crises experience showed that in traumatic loss the fact of blindness becomes one of the central problems in life experience and possibility of positive transformation and integration is less probable because loss of vision "completely changed their lives, former life meaning". People with congenital visual impairment, showing similarities with sighted in allocation of types of loss and crisis situations (loss of a loved one, family breakdown, etc. ), but in description of effects and what they do with experience - more active and positive view on situation, future perspective and own efforts to overcome difficulties, to care of others, fulfill personality work which actually makes it possible to transform the hardiness into resilience, positive outcome of the disaster.
\end{abstract}

Keywords: Hardiness, resilience, personality, work, visually, impaired. 
